\title{
Mycoplasma lipophilum sp. nov.
}

\author{
RICHARD A. DEL GIUDICE, ROBERT H. PURCELL, THEODORE R. CARSKI, \\ and ROBERT M. CHANOCK
}

Flow Laboratories, Inc., Rockville, Maryland 20852, National Institute of Allergy and Infectious
Disease, Bethesda, Maryland 20014, and Huntingdon Research Center, Baltimore, Maryland

Two Mycoplasma strains isolated from the human oral cavity exhibit cultural and serological properties distinguishing them from the known human Mycoplasma species. Further, a variety of cultural and serological procedures fail to identify the strains with any of a wide range of Mycoplasmatales tested. The strains are described as a new species under the name Mycoplasma lipophilum previously referred to as ( $M$. lipophilia) of the family Mycoplasmataceae. The type strain is MaBy (=ATCC 27104).

The name Mycoplasma lipophiliae was proposed for a new Mycoplasma species described at a scientific meeting, and the name was published in the proceedings of that meeting (R. A. Del Giudice and T. R. Carski, Bacterial Proc., p. 67, 1968). Rule 11 of the International Code of Nomenclature of Bacteria (16) is taken to mean that this did not constitute effective publication. The name $M$. lipophiliae, therefore, was not validly published and as such has no standing in bacteriological nomenclature. D. G. ff. Edward advised us that it would be grammatically correct to change the epithet lipophiliae to lipophilum so as to effect agreement of the specific epithet with the neuter gender of the generic name Mycoplasma. This does not constitute a name change since the name $M$. lipophiliae has no standing in nomenclature. Our purpose in this paper is to validly publish the name $M$. lipophilum and to provide a description of the species to which this name is applied.

\section{MATERIALS AND METHODS}

Bacterial strains. The Mycoplasmatales strains and antisera used in this study were reference reagents of the Research Resources Branch (RRB), National Institute of Allergy and Infectious Diseases, and the Bureau of Biologics, Food and Drug Administration, Bethesda, Md. The reagents were prepared under a Public Health Service contract and subsequently were certified by E. A. Freundt, Aarhus, Denmark.

Two Mycoplasma lipophilum strains were studied, namely MaBy, the type strain, and Jones. These strains have been deposited in the American Type Culture Collection (ATCC), Rockville, Md., under the numbers 27104 and 27790 , respectively. No other strains of this species are known. The Jones strain was isolated by D. K. Ford, Vancouver, Canada, from the throat of a patient ill with infectious mononucleosis. Ford recognized that the Jones strain was distinct from the other mycoplasmas of human origin when he supplied it to us for study.

Strain MaBy was isolated by one of us (R.A.D.) in 1964 from the sputum of a patient with primary atypical pneumonia. A few small colonies were obtained on plates streaked with sputum. Maintenance of this organism was difficult, requiring repeated agar-to-agar subcultures which produced only scanty growth. Not until after approximately 4 years could liquid cultures and heavy growth be obtained. The cultural properties reported herein, including the test for bacterial reversion, are the result of studies on an organism that has undergone 4 to 5 years of laboratory manipulation and adaptation to artificial media. It is uncertain if the currently reliable growth is due exclusively to adaptation on the part of the mycoplasma or to our own operational adaptation in selecting medium components which support this organism.

Media. Hayflick medium (1) of mycoplasma base medium (BBL, Division of BioQuest, Baltimore, Md.) was used for cultivation of the mycoplasmas. The Mycoplasma Broth Base medium (BBL no. 11458) was modified from the previously published formulations to contain (per liter): Myosate peptone, $5 \mathrm{~g}$; Biosate peptone, $10 \mathrm{~g}$; and sodium chloride, $5 \mathrm{~g}$. Agar base contained agar $(0.8 \%)$ (Oxoid Ionagar no. 2) in addition to the ingredients listed above. Neither the broth nor agar base contained the meat infusions usually found in mycoplasma basal media (9).

The complete medium consisted of the broth or agar base supplemented with $10 \%$ horse serum, $5 \%$ fresh yeast extract, $0.002 \%$ phenol red, $500 \mathrm{U}$ of penicillin per $\mathrm{ml}$, and $0.02 \%$ deoxyribonucleic acid (DNA) from calf thymus (Schwarz-Mann, Orangeburg, N.Y.). In preliminary studies, the growth of $M$. lipophilum and several other mycoplasmas was enhanced by DNA in media containing yeast extract. DNA enhancement varied with different lots of yeast. 
These results are in agreement with those previously reported $(5,8,12)$.

Electron microscopy. Young agar-grown colonies of $M$. lipophilum strain Jones were fixed in $5 \%$ glutaraldehyde in phosphate-buffered saline (PBS, pH 7.4) for $1 \mathrm{~h}$ and then stored in $0.22 \mathrm{M}$ sucrose in PBS. Fixed colonies were stained with $1 \%$ osmium tetroxide and Veronal buffer ( $\mathrm{pH} 7.4$ ) and dehydrated by passing through the following ethanol solutions: $35 \%, 70 \%$, $70 \%$ with saturated uranyl acetate, $95 \%$, and $100 \%$. The dehydrated specimens were passed through two changes of propylene oxide, one change of $50 \%$ propylene oxide, and 50\% Epon 812 before being embedded in double-strength Epon 812. Sections were cut with a glass knife on an ultra-microtome (PorterBlum, model MT-2) and examined with an electron microscope (Siemens America, Inc., New York, N.Y.: model Elmskopl-A).

Metabolism test. Metabolic activity was determined in a broth medium supplemented with either $0.5 \%$ glucose, $0.5 \%$ arginine, or $0.5 \%$ urea. A color change of the phenol red indicated acid production from glucose or ammonia production from arginine or urea. Controls consisted of unsupplemented broth, supplemented broth inoculated with strains of known metabolic activity, and uninoculated medium. Reduction of methylene blue and tetrazolium were observed directly by the color change of these indicators.

Since several mycoplasmas of human origin were found to grow better with cysteine (unpublished data), Hayflick liquid medium was supplemented with $0.5 \%$ cysteine for some tests.

Lipid staining. The lipid-staining properties were studied by incorporating fat-soluble stains in to an agar medium; this method was used by Minsley to differentiate mycobacteria (10). A stock solution of $0.5 \%$ Oil Red-O was prepared in acetone. A $1-\mathrm{ml}$ amount of the stock solution was added to $80 \mathrm{ml}$ of hot agar base. After the agar was autoclaved, the base was supplemented as indicated. Paper disks saturated with $0.1 \%$ solutions of various lipid stains in acetone were air-dried, autoclaved, and stored in. vials. The stain-impregnated disks were placed on the agar surface after inoculation with the organism. Colonies growing on agar containing Oil Red-O or growing near stain-impregnated disks were incubated and examined daily for coloration. Stains tested by the disk method were Oil Red-O, Sudan Black, Sudan III, and Sudan IV.

Colonial hemadsorption test. Petri plates with young colonies growing on agar were flooded with a $0.5 \%$ suspension of erythrocytes in $0.01 \mathrm{M}$ PBS at pH 7.3 and incubated for $15 \mathrm{~min}$ at ambient temperature. The unadsorbed cells were resuspended with a swirling motion, and the cell suspension was decanted. The plates were washed gently with PBS and examined with a microscope for adsorption of erythrocytes to colonies. Tests were made with sheep, guinea pig, human type $\mathrm{O}$, and chicken erythrocytes; $M$. pneumoniae was used as a positive control in all tests.

Hemolysis test. The test for hemolysis was similar to that described by Somerson et al. (14) and Clyde (4). Guinea pig and sheep erythrocytes were used, and the results were compared with those obtained with known hemolytic mycoplasmas.
Other. Filterability was determined by counting colony-forming units (CFU) before and after passing a broth culture through $0.45 \mu \mathrm{m}$ and $0.22 \mu \mathrm{m}$ membrane filters. Bacterial reversion was tested by making six subcultures on a medium free of bacterial inhibitors.

Growth inhibition. Growth inhibition (GI) tests were performed by the serum disk method of Clyde (4).

Immunofluorescence test and microscopy. Immunofluorescence (IF) procedures were similar to those previously described (7). Unfixed colonies growing on agar were stained with fluorescein-conjugated antimycoplasma globulin and examined in situ with incident ultraviolet illumination.

Fluorescein conjugates prepared with antisera from goats or rabbits immunized with horse-serum-grown antigens were adsorbed with normal horse serum before staining.

Broth cultures were stained by a modification of the method of Clark et al. (2). Broth cultures $(10 \mathrm{ml})$ plus conjugate $(0.1 \mathrm{ml})$ were incubated for $30 \mathrm{~min}$ at ambient temperature, centrifuged at $3,000 \mathrm{rpm}$ for 30 min, washed with 2 volumes of PBS, and suspended in approximately $0.5 \mathrm{ml}$ of PBS. Wet-slide and cover-slip preparations of the stained suspensions were examined with a microscope by phase-contrast or dark-field tungsten illumination and by ultraviolet excitation. Gram-stained preparations were examined also.

Complement fixation tests. Complement-fixing (CF) antigens of the mycoplasmas were prepared in rabbit infusion broth and tested against hyperimmune sera prepared in rabbits as described previously (11). $\mathrm{CF}$ antigens and rabbit hyperimmune sera were prepared by one of us (R.M.C.), without reference to the RRB reagents. CF tests were performed as described by Purcell et al. (11).

Metabolic inhibition tests. Metabolic-inhibition (MI) tests were performed as previously described (15) with the use of the rabbit hyperimmune sera prepared as above and with pools of mycoplasmas prepared independently of the RRB reagents.

\section{RESULTS}

Ultrastructure. Electron microscopy revealed pleomorphic, granular bodies, approximately 130 to $1,500 \mathrm{~nm}$ in diameter (Fig. 1). These bodies were bounded by a three-layered unit membrane and closely resembled other wellcharacterized mycoplasmas in morphology. There was no evidence of a cell wall surrounding the limiting membrane.

Metabolic reactions. $M$. lipophilum metabolized arginine, as evidenced by a rise in $\mathrm{pH}$ of broth cultures supplemented with this substrate. The production of ammonia by $M$. lipophilum was enhanced by DNA and cysteine but not by yeast extract. No change in $\mathrm{pH}$ was detected when either glucose or urea was employed as substrate. Neither methylene blue nor tetrazolium was reduced. 
Lipid straining. M. lipophilum colonies growing near a paper disk impregnated with Oil Red-O or Sudan Black took up the stain and appeared red or black, respectively. The colonies were stained as soon as they became microscopically visible, after approximately 48 $h$ of growth. On continued incubation, the color became more intense and progressively involved colonies farther from the disk. The appearance of colonies stained with Sudan IV was similar to that of colonies stained with Oil Red-O; Sudan IV, however, did not appear to diffuse as well through the agar. Staining with Sudan III was barely detectable. None of the other mycoplasmas of human or animal origin listed in Table 1 demonstrated a strong affinity for any of the lipid stains. After prolonged incubation, a few species, particularly " $M$. orale type 2 ," showed weak staining.

The effect of lipid staining for detection of $M$. lipophilum in mixed culture was evaluated by the use of plates inoculated with intentionally mixed cultures of $M$. lipophilum and other human mycoplasmas. After a few days of incubation with Oil Red-O, M. lipophilum was detected by the differential staining reaction. Figure 2 shows the contrast of red colonies of $M$. lipophilum and colorless colonies of " $M$. orale type 3" growing near an Oil Red-O disk.

The diffusion of the lipid stains into the agar seemed not to affect mycoplasma growth or viability; colonies of all strains tested grew in uninhibited fashion up to the disk. Furthermore, single, intensely-stained $M$. lipophilum colonies could still be subcultured to fresh plates.

The Oil Red-O staining reaction of colonies growing on agar containing the stain was similar to that of colonies near a stain-impregnated disk.

Reactions with erythrocytes. Colonies of $M$. lipophilum failed to adsorb human, sheep, guinea pig, or chicken ery throcytes.

$M$. lipophilum produced hemolytic plaques in agar overlays of guinea pig but not sheep erythrocytes; these plaques, however, could not

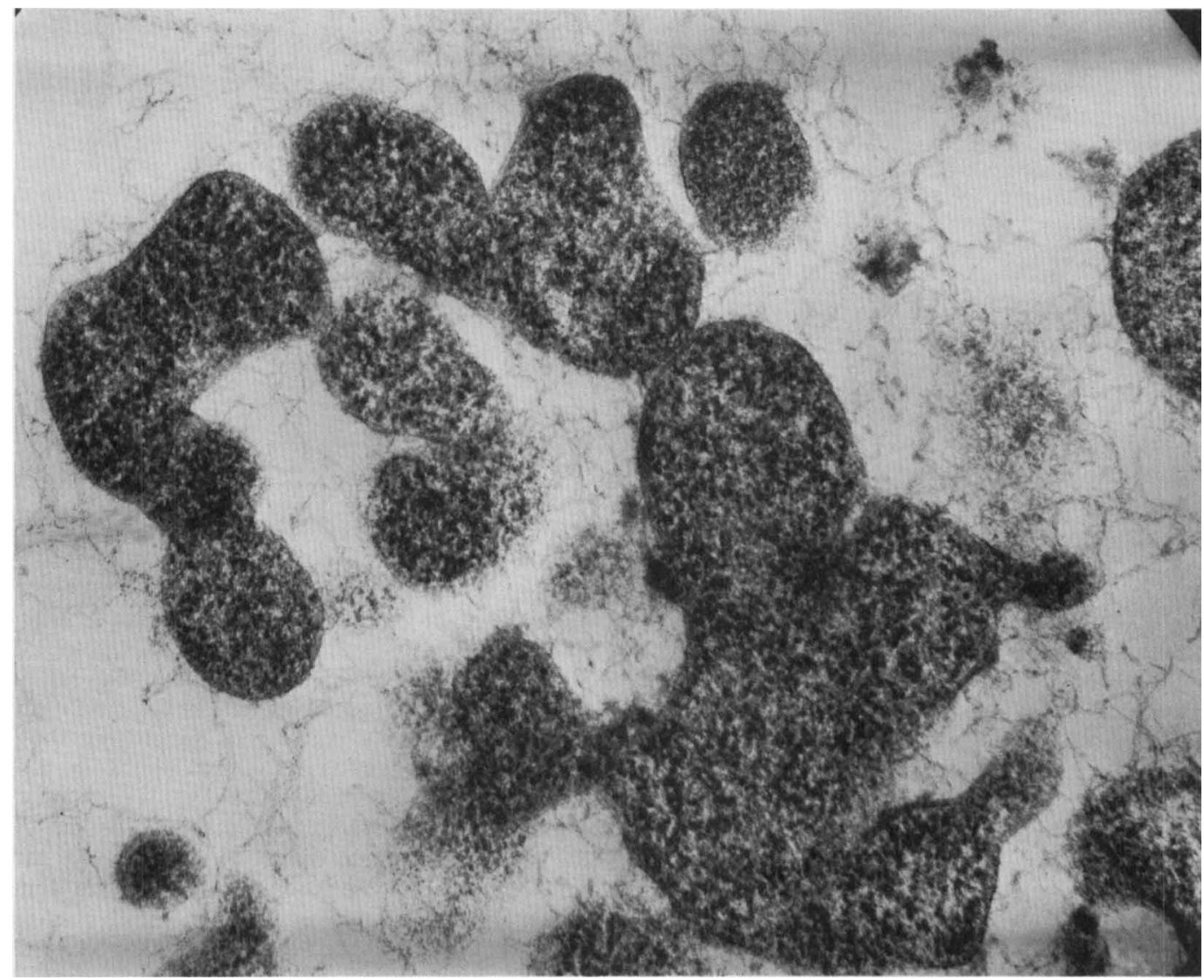

FIG. 1. Thin-section electron micrograph of agar-grown $M$. lipophilum colony. $\times 60,000$. 
TABLE 1. Serological reactions of the MaBy and Jones strains of $M$. lipophilum with antisera directed against 32 species of Mycoplasmatales by using immunofluorescence (IF), growth inhibition (GI), metabolic inhibition (MI), and complement fixation (CF)

\begin{tabular}{|c|c|c|c|c|c|c|c|c|c|c|}
\hline & & \multicolumn{9}{|c|}{ Antibody titer (reciprocal) against indicated strain } \\
\hline \multicolumn{2}{|c|}{$\begin{array}{l}\text { Antiserum prepared against } \\
\text { indicated Mycoplasmatales }\end{array}$} & \multicolumn{4}{|c|}{$\begin{array}{l}\text { Homologous } \\
\text { antigen }\end{array}$} & \multicolumn{3}{|c|}{$\begin{array}{l}\text { MaBy } \\
\text { antigen }\end{array}$} & \multicolumn{2}{|c|}{$\begin{array}{l}\text { Jones } \\
\text { antigen }\end{array}$} \\
\hline Species & Strain & IF & GI & MI & $\mathrm{CF}$ & IF & GI & MI & MI & $\mathrm{CF}$ \\
\hline $\begin{array}{l}\text { Mycoplasma lipo- } \\
\text { philum }\end{array}$ & MaBy & 640 & + & 160 & & & + & 160 & 160 & \\
\hline M. lipophilum & Jones & 160 & + & 1280 & 640 & 640 & + & 640 & 1280 & 640 \\
\hline M. pneumoniae & FH & 320 & + & 2560 & 5120 & 80 & - & $<10$ & 40 & $<40$ \\
\hline M. fermentans & PG18 & 640 & + & 1280 & 640 & $<10$ & - & $<10$ & $<10$ & 80 \\
\hline$M$. salivarium & PG20 & 1280 & + & 20480 & 2560 & 40 & - & $<10$ & $<10$ & $<40$ \\
\hline$M$. hominis & PG 21 & 640 & + & 10240 & 1280 & $<10$ & - & $<10$ & $<10$ & $<40$ \\
\hline M. "orale type 1 " & $\mathrm{CH} 19$ & 640 & + & 5120 & 640 & $<10$ & - & $<10$ & $<10$ & $<40$ \\
\hline$M$. "orale type 2 " & $\mathrm{CH} 20$ & 1280 & + & 163840 & 2560 & 40 & - & $<10$ & $<10$ & $<40$ \\
\hline M. pulmonis & ASH & 320 & + & 320 & 1280 & 40 & - & $<10$ & $<10$ & $<40$ \\
\hline M. arthritidis & PG6 & 1280 & + & 1280 & 640 & $<10$ & - & $<10$ & $<10$ & $<40$ \\
\hline M. hyorhinis & BTS7 & 2560 & + & 2560 & 2560 & 40 & - & $<10$ & $<10$ & \\
\hline Acholeplasma granularum & BTS39 & 640 & + & 5120 & 5120 & $<10$ & - & $<10$ & $<10$ & $<40$ \\
\hline A. laidlawii & PG8 & 1280 & + & 320 & 160 & $<10$ & - & $<10$ & $<10$ & 80 \\
\hline M. spumans & PG13 & 2560 & + & 640 & 640 & $<10$ & - & $<10$ & $<10$ & $<40$ \\
\hline M. canis & PG14 & 320 & + & 2560 & 320 & $<10$ & - & $<10$ & $<10$ & $<40$ \\
\hline M. maculosum & PG 15 & 1280 & + & 2560 & 40 & $<10$ & - & $<10$ & $<10$ & $<40$ \\
\hline M. gallinarum & PG16 & 1280 & + & 1280 & 640 & $<10$ & - & $<10$ & $<10$ & $<40$ \\
\hline$M$. iners & PG30 & 1280 & + & 1280 & 320 & $<10$ & - & $<10$ & $<10$ & $<40$ \\
\hline M. gallisepticum & PG31 & 1280 & + & 1280 & 160 & $<10$ & - & $<10$ & $<10$ & $<40$ \\
\hline M. meleagridis & 17529 & 2560 & + & & & 10 & - & & & \\
\hline M. anatis & 1340 & 1280 & + & & & 40 & - & & & \\
\hline M. neurolyticum & TypeA & 1280 & + & 640 & 2560 & $<10$ & - & $<10$ & $<10$ & $<40$ \\
\hline M. bovigenitalium & PG11 & 1280 & + & 5120 & 160 & 10 & - & $<10$ & $<10$ & $<40$ \\
\hline M. bovirhinis & PG43 & 1280 & + & & & 10 & - & & & \\
\hline M. "orale type 3" & DC333 & 1280 & + & 10240 & 640 & 40 & - & $<10$ & $<10$ & $<40$ \\
\hline M. arginini & $\mathrm{G} 230$ & 2560 & + & & & $<10$ & - & & & \\
\hline M. primatum & HRC292 & 640 & + & & & 40 & - & & & \\
\hline M. edwardii & PG24 & 320 & + & & & 20 & - & & & \\
\hline M. conjunctivae & 581 & 1280 & + & & & $<10$ & - & & & \\
\hline M. gateae & MART & 1280 & + & & & $<10$ & - & & & \\
\hline M. felis & $\mathrm{CO}$ & 1280 & + & & & 10 & - & & & \\
\hline A. axanthum & S743 & 160 & - & & & 40 & - & & & \\
\hline M. caviae & G122 & 320 & + & & & 10 & - & & & \\
\hline M. feliminutum & Ben & 2560 & + & & & 10 & - & & & \\
\hline
\end{tabular}

be consistently reproduced.

Other cultural properties. $M$. lipophilum grew better in an atmosphere of $5 \% \mathrm{CO}_{2}$ and $95 \%$ $\mathrm{N}_{2}$ rather than aerobically. Colonies first appeared within 24 to $48 \mathrm{~h}$ and developed to a size of 400 to $500 \mu \mathrm{m}$ in 7 days. Growth of $M$. lipophilum was associated with a heavy production of film (Fig. 3) which spread out over the surface of the agar; spots appeared within the agar containing colonies of $M$. lipophilum. Film radiating from single colonies or covering areas of heavy growth was macroscopically conspicuous. It appeared as a band of haze surrounding areas of growth. In addition to the film and spots, older colonies developed numerous internal particles which were refractile or crystalline in appearance (Fig. 4). The granular sediment from broth cultures was gram negative.

Specific fluorescein-labeled antibody failed to react with the particles within the colony or the film on the surface of the agar. Furthermore, neither the particles nor the film displayed an affinity for lipid stain.

Film similar to that seen on the surface of the agar could also be seen floating on the surface of broth cultures. Broth cultures generally contained macroscopically visible clumps of organisms which settled to the bottom of the culture tube. Some of these clumps formed microcolonies which adhered to the glass. Broth cultures treated with fluorescent antibody 
revealed characteristic granular clusters and pleomorphic coccoid forms which reacted strongly with the conjugate. In addition, nonstaining structures in the form of spheres ( 5 to $10 \mu \mathrm{m}$ in diameter) and rough rods (1 to $2 \mu \mathrm{m}$ in diameter and $20 \mu \mathrm{m}$ in length) were

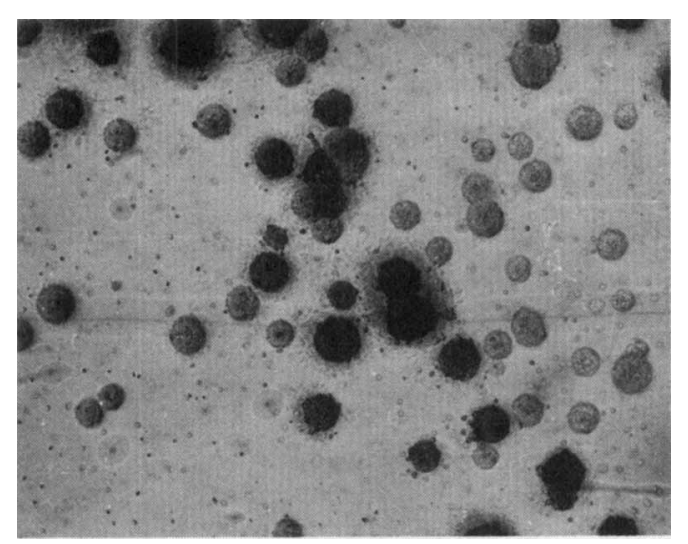

FIG. 2. Mixed culture of Mycoplasma lipophilum (strain MaBy) and "M. orale type 3"' (strain DC 333) growing near a disk saturated with Oil Red-O. The red colonies of strain MaBy show in dark contrast. $\times 125$.

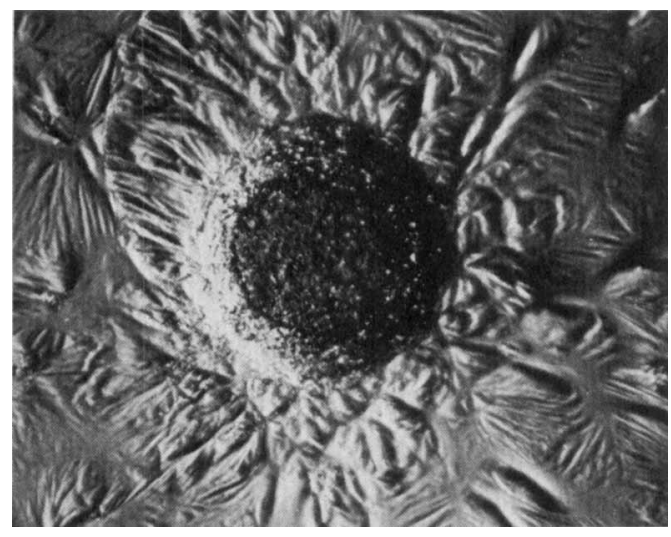

FIG. 3. Mycoplasma lipophilum colony with the development of film on the agar surface. Refractile particles within the colony are demonstrated by oblique illumination. $\times 250$. observed. These nonantigenic structures were so numerous that they appeared to comprise nearly half of the mass of sedimented material from $M$. lipophilum broth cultures. The rods and spheres found in broth cultures appeared similar to those which developed in agar-grown colonies. These structures did not immunofluoresce but demonstrated a bright blue auto-fluorescence. Small immunofluorescent particles adhered to some of the rods.

Among the mycoplasmas of human origin, the cultural properties of $M$. lipophilum resembled those of " $M$. orale type 3 " and, to a lesser degree, $M$. salivarium.

$M$. lipophilum suspensions passed through 0.45 and $0.22 \mu \mathrm{m}$ membrane filters. The titer decreased from $10^{6}$ to $10^{1} \mathrm{CFU} / \mathrm{ml}$ on passing a $0.22 \mu \mathrm{m}$ filter. Six subcultures on a medium free of bacterial inhibitors did not induce morphological instability.

Serology. The MaBy and Jones strains of $M$. lipophilum were antigenically related by the IF, GI, and MI tests (Table 2). The end point titers for a given serum varied no more than twofold

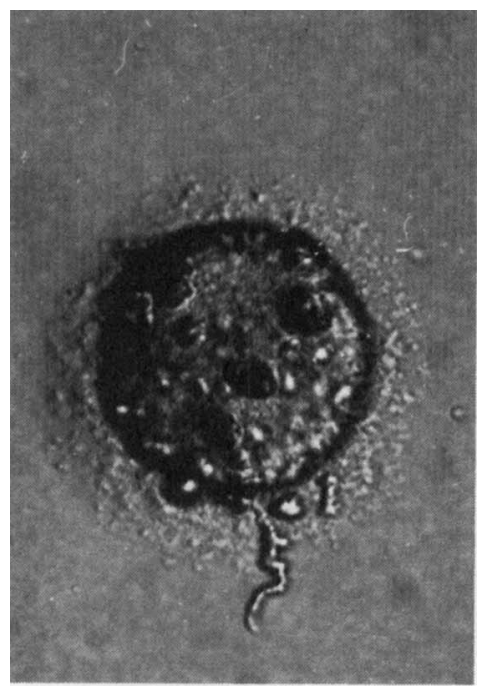

FIG. 4. M. lipophilum colony showing nonantigenic internal particles. $\times 250$.

TABLE 2. Serological relationship of the MaBy and Jones strains of Mycoplasma lipophilum by immunofluorescence (IF), growth inhibition (GI), and metabolic inhibition (MI)

\begin{tabular}{c|c|c|c|c|c|c}
\hline \multirow{2}{*}{ M. lipophilum strain } & \multicolumn{4}{|c|}{ Antibody titer (reciprocal) for indicated antisera } \\
\cline { 2 - 7 } & \multicolumn{2}{|c|}{ IF } & \multicolumn{2}{|c|}{ GI } & \multicolumn{3}{|c}{ MI } \\
\cline { 2 - 8 } & MaBy & Jones & MaBy & Jones & MaBy & Jones \\
\hline MaBy & 640 & 80 & + & + & 160 & 640 \\
Jones & 320 & 160 & + & + & 160 & 1280 \\
\hline
\end{tabular}


for either strain in the IF and MI tests. The GI results (not presented quantitatively) were in agreement with those of the above-mentioned tests.

Both strains of $M$. lipophilum were antigenically distinct from strains of 32 named species of the order Mycoplasmatales. Antisera directed against the 32 species listed in Table 1 failed to react significantly with the $\mathrm{MaBy}$ strain in the IF, GI, or MI tests or with the Jones strain in the CF or the MI test. Antigens of these 32 species (Table 3) showed no

TABLE 3. Serological reactions of $M$. lipophilum antisera with 32 species of Mycoplasmatales using immunofluorescence (IF), growth inhibition (GI), metabolic inhibition (MI), and complement fixation (CF)

\begin{tabular}{|c|c|c|c|c|c|}
\hline \multirow{2}{*}{\multicolumn{2}{|c|}{ Mycoplasmatales antigen }} & \multicolumn{4}{|c|}{$\begin{array}{l}\text { Antibody titer (re- } \\
\text { ciprocal) with in- } \\
\text { dicated antisera }\end{array}$} \\
\hline & & \multicolumn{2}{|c|}{ MaBy } & \multicolumn{2}{|c|}{ Jones } \\
\hline Species & Strain & IF & GI & MI & $\mathrm{CF}$ \\
\hline $\begin{array}{l}\text { Mycoplasma lipo- } \\
\text { philum }\end{array}$ & MaBy & 640 & + & 640 & \\
\hline M. lipophilum & Jones & 320 & + & 1280 & 640 \\
\hline$M$. pneumoniae & FH & $<10$ & - & $<10$ & $<40$ \\
\hline M. fermentans & PG18 & $<10$ & - & $<10$ & $<40$ \\
\hline$M$. salivarium & PG20 & 20 & - & $<10$ & $<40$ \\
\hline M. hominis & PG21 & $<10$ & - & $<10$ & $<40$ \\
\hline M. "orale type $1 "$ & $\mathrm{CH} 19$ & $<10$ & - & $<10$ & $<40$ \\
\hline M. "orale type 2 " & $\mathrm{CH} 20$ & $<10$ & - & $<10$ & $<40$ \\
\hline M. pulmonis & $\mathrm{ASH}$ & $<10$ & - & $<10$ & $<40$ \\
\hline M. arthritidis & PG6 & $<10$ & - & $<10$ & $<40$ \\
\hline M. hyorhinis & BTS7 & $<10$ & - & $<10$ & $<40$ \\
\hline Acholeplasma & & & & & \\
\hline granularum & BTS39 & $<10$ & - & $<10$ & $<40$ \\
\hline A. laidlawii & PG8 & $<10$ & -1 & $<10$ & $<40$ \\
\hline M. spumans & PG13 & $<10$ & - & $<10$ & $<40$ \\
\hline M. canis & PG14 & $<10$ & - & $<10$ & $<40$ \\
\hline M. maculosum & PG15 & $<10$ & - & $<10$ & $<40$ \\
\hline M. gallinarum & PG16 & $<10$ & - & $<10$ & 80 \\
\hline$M$. iners & PG30 & 40 & - & $<10$ & $<40$ \\
\hline M. gallisepticum & PG31 & $<10$ & - & & \\
\hline M. meleagridis & 17529 & $<10$ & - & & \\
\hline$M$. anatis & 1340 & $<10$ & - & & \\
\hline$M$. neurolyticum & Type A & $<10$ & - & $<10$ & $<40$ \\
\hline M. bovigenitalium & PG11 & $<10$ & - & $<10$ & $<40$ \\
\hline M. bovirhinis & PG43 & $<10$ & - & & \\
\hline$M$. "orale type $3 "$ & DC333 & $<10$ & - & $<10$ & \\
\hline M. arginini & G230 & $<10$ & - & & $<40$ \\
\hline M. primatum & HRC292 & $<10$ & - & & \\
\hline M. edwardii & PG24 & $<10$ & - & & \\
\hline M. conjuctivae & 581 & $<10$ & - & & \\
\hline M. gateae & MART & $<10$ & - & & \\
\hline$M$. felis & $\mathrm{CO}$ & $<10$ & - & & \\
\hline A. axanthum & S743 & $<10$ & - & & \\
\hline$M$. caviae & G122 & $<10$ & - & & \\
\hline M. feliminutum & Ben & $<10$ & - & & \\
\hline
\end{tabular}

high-level cross-reactions with antisera directed against strain MaBy in the IF or GI test nor with antisera directed against strain Jones in the $\mathrm{CF}$ or MI test.

\section{DISCUSSION}

$M$. lipophilum appears to occur rarely in man. Only two strains have been recognized despite efforts in a number of laboratories to define the human Mycoplasma flora, and both of these strains were difficult to adapt to artificial media, continuing to be fastidious even after prolonged serial passage. Speculation then arises concerning the failure to isolate more strains of this species. Deficiencies in the media commonly used for mycoplasma isolation may account for this failure. Recent studies show that certain strains of $M$. hyorhinis growing in tissue culture are noncultivable by standard isolation procedures $(8 \mathrm{a})$. The possibility that the human oral cavity is not the primary habitat of $M$. lipophilum must also be considered. $M$. primatum (strain Navel) was first isolated from a human, and 13 years passed before this species was recognized as part of the simian Mycoplasma flora (6). Regarding host specificity, M. lipophilum and $M$. pneumoniae are the only uniquely human mycoplasmas, as all of the other so-called human mycoplasmas are found in nonhuman primates.

The selective vital staining of $M$. lipophilum colonies with lipid-soluble stains distinguishes it from other mycoplasmas of human origin. The nature of the differential reaction may be quantitative rather than qualitative, since several other species of Mycoplasma were stained after prolonged incubation. Two important advantages of this test are single-colony selectivity and minimal effect on viability. The method could, therefore, be useful for presumptive identification and purifications of $M$. lipophilum in mixed culture.

The properties of $M$. lipophilum are compatible with those of the order Mycoplasmatales, and the growth requirement for cholesterol (13) places this species in the family Mycoplasmataceae.

The following is a summary description of $M$. lipophilum sp. nov.:

(lipo'phi. lum. Gr. noun lipus animal fat; Gr. adj. philus loving; M.L. adj. lipophilus fatloving)

Minute elements unresolved by light microscopy. Gram negative.

Agar colonies. Colonies are yellow-brown, have a rough surface and assume fried-egg morphology under optimal conditions. 
Liquid cultures. Slight turbidity; microcolonies, both free and adherent to the glass, are formed.

Film and spots. Heavy production of film and spots in liquid as well as solid media.

Lipid stain. Colonies growing on agar accept lipid-soluble pigments; this is the most distinctive property of the species.

Glucose. No acid produced.

Urea. Not hydrolyzed.

Arginine is hydrolyzed.

Methylene blue is not reduced.

Anaerobic or microaerophilic.

Hemadsorption. No adsorption of human, guinea-pig, chicken, or sheep erythrocy tes.

Hemolysis. Small, variable plaques are produced in agar overlays of guinea-pig but not sheep ery throcytes.

Serology. Unique by immunofluorescence, complement-fixation, metabolic-inhibition, and growth-inhibition tests.

Pathogenicity. Unknown.

Source. Isolated from human respiratory secretions.

Habitat. Uncertain.

Type strain. MaBy (=ATCC 27104). The characters of the type strain are the same as those given above for the species. The type strain (MaBy) does not differ from the Jones strain.

\section{ACKNOWLEDGMENTS}

This work was initiated in A. I. Braude's laboratory at the University of Pittsburgh. E. B. Rotherman provided the clinical diagnosis of primary atypical pneumonia and the specimen from which strain MaBy was isolated. J. Dees performed the electron microscope analyses of the specimens.

Part of the work upon which this publication is based was performed pursuant to Public Health Service contract no. FDA $74-41$ from the Food and Drug Administration and to previous Public Health Service contracts.

\section{REPRINT REQUESTS}

Address reprint requests to: R. A. Del Giudice, Flow Laboratories, Inc., 1710 Chapman Ave., Rockville, Md. 20852.

\section{LITERATURE CITED}

1. Chanock, R. M., L. Hayflick, and M. F. Barile. 1962. Growth on artificial medium of an agent associated with atypical pneumonia and its identification as a PPLO. Proc. Nat. Acad. Sci. U.S.A. 48:41-49.

2. Clark, H. W., J. S. Bailey, R. C. Fowler, and T. M. Brown. 1963. Identification of Mycoplasmataceae by the fluorescent antibody method. J. Bacteriol. 85:111-118.

3. Clyde, W. A. 1963. Hemolysis in identifying Eaton's pleuropneumonia-like organisms. Science 139:55.

4. Clyde, W. A., Jr. 1964. Mycoplasma species identification based upon growth inhibition by specific antisera. J. Immunol. 92:958-965.

5. Crowther, S., and B. C. J. G. Knight. 1956. The effect of nucleic acid fragments on the growth of a pleuropneumonia-like organism. J. Gen. Microbiol. 14:vii.

6. Del Giudice, R. A., T. R. Carski, M. F. Barile, R. M. Lemcke, and J. G. Tully. 1971. Proposal for classifying human strain Navel and related simian my coplasmas as Mycoplasma primatum sp. $\mathrm{n}$. J. Bacteriol. 108:439-445.

7. Del Giudice, R. A., N. F. Robillard, and T. R. Carski. 1967. Immunofluorescense identification of Mycoplasma on agar by use of incident illumination. J. Bacteriol. 93: 1205-1209.

8. Edward, D. G. ff. 1947. A selective medium for pleuropneumonia-like organisms. J. Gen. Microbiol. 1 : 238-243.

8a.Hopps, H. E., B. C. Meyer, M. F. Barile, and R. A. Del Giudice. 1974. Problems concerning "noncultivable" mycoplasma contaminants in tissue cultures. Ann. N. Y. Acad. Sci. 225: 265-276.

9. Morton, H. E., P. F. Smith, and P. R. Leberman. 1951. Investigation of the cultivation of pleuropneumonia-like organisms from man. Amer. J. Syph. Gonor. Vener. Dis. 35: 361-369.

10. Minsley, N. M. 1964. A differential medium for mycobacteria. Amer. Rev. Resp. Dis. 89: 108110.

11. Purcell, R. H., D. Taylor-Robinson, D. Wong, and R. M. Chanock. 1969. Serology of mycoplasmas of man, p. 221-264. In L. Hayflick (ed.), The Mycoplasmatales and the L-phase of bacteria. Appleton-Century Crofts, New York.

12. Razin, S. 1962. Nucleic acid precursor requirements of Mycoplasma laidlawii. J. Gen. Microbiol. 28:243-250.

13. Razin, S., and J. G. Tully, 1970. Cholesterol requirement of mycoplasmas. J. Bacteriol. 102:306-310.

14. Somerson, N., R. H. Purcell, D. Taylor-Robinson, and R. M. Chanock. 1965. Hemolysin of $\mathrm{MycO}$ plasma pneumoniae. J. Bacteriol. 89:813-818.

15. Taylor-Robinson, D., R. H. Purcell, D. C. Wong, and R. M. Chanock. 1966. A colour test for the measurement of antibody to certain Mycoplasma species based upon the inhibition of acid production. J. Hyg. Camb. 64:91-104. 